\title{
Influence of packaging material, storage condition and duration on quality attributes of osmo-cum-microwave dehydrated mushroom flakes
}

\author{
Ramya H.G. ${ }^{1 *}$, Satish Kumar ${ }^{1}$ and Vidisha Tomer ${ }^{2}$ \\ ${ }^{1}$ Department of Processing and Food Engineering, COAE\&T, Punjab Agriculture University, Ludhiana-141004 \\ (Punjab) INDIA \\ ${ }^{2}$ Department of Food and Nutrition, COHSc, Punjab Agriculture University, Ludhiana-141004 (Punjab), INDIA \\ *Corresponding author. E-mail: ramyarinda@gmail.com
}

Received: October10, 2015; Revised received: April 22, 2016; Accepted: December 8, 2016

\begin{abstract}
The present article investigates influence of packaging material, storage condition and duration on quality attributes of osmo-cum-microwave dehydrated Pleurotus sajor-caju mushroom flakes during storage. Oyster mushrooms were dried by microwave drying technique to a moisture content of $6 \%$ (w.b.) succeeding osmosis. The ultimate superior quality dried product obtained through optimization was stored in different packaging material for confined duration of three months at different storage conditions. Various quality attributes that assist in bestowal of overall consumer acceptability were studied during storage period. The present research study revealed that mushroom flakes were highly acceptable upto two months of storage that was packed in high density polyethylene by retaining much of the quality attributes. The outcome of the present investigation perhaps supportive for those involved in the post-harvest processing and value addition of oyster mushrooms.
\end{abstract}

Keywords: Microwave dehydration, Osmosis, Oyster mushrooms, Quality attributes, Storage

\section{INTRODUCTION}

Mushrooms are macro fungi and are recognized as important food items from antiquity. Consumption of mushrooms has been augmented from decades owing to their striking role in human health and nutrition (Khan et al., 2008). Mushroom intake has been shown to be constructive in weight management, immune function and quality of life. Mushroom intake encouragingly influence muscle function and balance recital in older men and women (Williams et al., 2014). In infancy, compiled evidence suggests that culinarymedicinal mushrooms also partake an imperative role in the preclusion of many age-associated neurological dysfunctions, including Alzheimer's and Parkinson's diseases (Phan et al., 2014). Macro fungi from the genus pleurotus, extensively known as oyster mushrooms are preferred by many people for their delicate taste, mild yet chewy texture and inimitable aroma. Many species of oyster mushrooms are of highly medicinal significance. Pleurotus sajor-caju inhibits hypertensive effects through its active ingredients, which affect the rennin-angio- tension system (Chang, 1996). The $\beta$ -glucan-rich polysaccharides from $P$. sajor-caju is a novel 5'-AMP-kinase activator, was shown to be valuable in the formulation of nutraceuticals and functional food for the deterrence and remedy for diabetes mellitus (Kanagasabapathy et al., 2014). Mushroom production has turn out to be developing small-scale business in India as the demand is increasing from last two decades. Mushroom cultivation is a matter of practice and technical knowledge rather than labour demanding farming, with a high value of revenue in short span of time (Maheshwari, 2013). These mushrooms are exceedingly perishable because of their high initial moisture content and delicate nature and cannot be stored for more than 24 hours at ambient climate (25 to $30^{\circ} \mathrm{C}$ ) (Mattila et al., 2001). So, in order to augment produce shelf-life and to gratify consumer's consumption requirements, post-harvest processing becomes requisite without ado after harvesting.

Yet, Consumer demand has increased for processed food products rather than fresh produce that keep more of their original attributes. This necessitates the development of maneuver that curtails the adverse effects in processing. The upshot of food processing on finished product quality, ultimately establishes the usefulness and commercial feasibility of that unit process operation. Drying is the most widespread way to preserve agricultural products for subsequent use. Drying foods is rapid, simple, safe and easy to carry out. It trims down the moisture content and so hinders microbial growth and averts certain biochemical changes extending the shelf-life of the product. This facilitates in ease of handling the processed product (Chua et al., 2001). Osmotic dehydration is one of most important complementary food preservation approach in processing of dehydrated foods, as it bestow some benefits akin to trim down the damage of heat to the flavour, colour, restraining the browning of enzymes and reduces the 
energy costs (Kaushal and Sharma, 2014). Osmotic dehydration trim down up to $50 \%$ weight of fresh vegetables and fruits resulting in semidried food stuffs by lessening the load of mechanical drying and freezing without causing superfluous changes in texture (Rastogi and Raghavararo, 1997; Petrotos and Lazarides, 2001). The osmotic treatment has been used as a pre-step before drying because it boosts up nutritional, organoleptic properties of foods. Use of microwave is considered as the fourth generation drying technology (Vega et al., 2001). Electromagnetic energy at 915 and $2450 \mathrm{MHz}$ can be absorbed by water contained in food materials or other substances, and converted into heat. Because waves can penetrate directly into the material, heating is volumetric (from inside out) and provides fast and uniform heating throughout the entire product. The quick energy absorption by water molecules causes rapid water evaporation (resulting in higher drying rates of food), creating an outward flux of rapidly escaping vapour. Many mechanical drying methods including airflow drying, vacuum drying, and freeze-drying, result in low drying rates in the falling rate period of drying (Clary et al., 2005). In addition to improving the drying rate, this outward flux can help to prevent the shrinkage of tissue structure, which prevails in most conventional air drying techniques. Hence better rehydration characteristics may be expected in microwave dried products. Microwave processes offer a lot of advantages such as less start up time, faster heating, energy efficiency (most of the electromagnetic energy is converted to heat), space savings, precise process control and food product with better nutritional quality (Khraisheh et al., 1997; Prabhanjan et al., 1995). The food processing industries are the predominant consumer of microwave energy, where it is engaged for cooking, thawing, tempering, drying, freeze-drying, and sterilization, baking, heating or re-heating (Cui et al., 2004).

Management of initial moisture content and its migration during storage is critical to the quality, permanence and safety of foods. The packaging must endow with a good moisture barrier, especially to protect foods from excessive drying out, which adversely affects both texture and taste. Food degradation during storage can be greatly influenced by means of a proper choice of the packaging material and atmosphere. A few studies are reported for the drying kinetics of oyster mushrooms. But, studies on influence of storage conditions on quality attributes of dehydrated mushroom flakes are scanty. So, the present study focused upon the influence of osmo-cum-microwave dehydration on the quality of stored oyster mushroom flakes in different packaging material for different time interval at refrigerant and ambient storage conditions.

\section{MATERIALS AND METHODS}

The finer quality salted oyster (Pleurotus sajor-caju) mushroom flakes were obtained through optimization of osmo-cum-microwave dehydration of mushrooms. These flakes were stored in 100 gauge $(25 \mathrm{~mm})$ packaging materials; low density poly ethylene (LDPE) having water vapour transmission rate (WVTR) of $6-23 \mathrm{~g} / \mathrm{m}^{2} /$ day and high density poly ethylene (HDPE) having water vapour transmission rate (WVTR) of 4-10 $\mathrm{g} / \mathrm{m}^{2} / \mathrm{day}$, and kept under refrigerated and ambient storage conditions for three months. The quality attributes of stored flakes like colour, texture, rehydration ratio, moisture content, water activity, ascorbic acid and overall acceptability were evaluated at regular interval of fifteen days along storage period of three months. Experimentation was carried out at quality analysis and Food Engineering Laboratory, Department of Processing and Food Engineering, Punjab agricultural University, Ludhiana.

Evaluation of quality attributes: The quality attributes those were analyzed during storage period were colour, texture, rehydration ratio, moisture content, water activity, ascorbic acid and overall acceptability.

Colour: The colour reader CR-10 (Konica Minolta Sensing Inc. USA) was used for the measurement of colour of the oyster mushroom flakes. Colour parameters ( $\mathrm{L}, \mathrm{a}$ and $\mathrm{b})$ of the flakes were recorded at $\mathrm{D}$ $65 / 10^{\circ}$, under proper lighting at regular intervals. The $\Delta \mathrm{a}, \Delta \mathrm{b}, \Delta \mathrm{L}$ and Colour change $(\Delta \mathrm{E})$ was also calculated for each experiment using following expression. Color change $\Delta \mathrm{E}=$

$$
\sqrt{\left(L_{0}-L\right)^{2}+\left(a_{0}-a\right)^{2}+\left(b_{0}-b\right)^{2}} \text {, }
$$

Where, $\mathrm{L}$ is degree of lightness to darkness, $\mathrm{L}_{0}$ is initial value of $\mathrm{L}$, $\mathrm{a}$ is degree of redness to greenness, $\mathrm{a}_{0}$ is initial value of $a, b$ is degree of yellowness to blueness and $b_{0}$ is initial value of $b$. Furthermore, other colour parameters such as chroma and hue were also calculated. Chroma (C) indicates colour saturation which is proportional to its intensity:

$$
\text { Chroma }(c)=\sqrt{\mathrm{a}^{2}+\mathrm{b}^{2}}
$$

For the hue value (h), an angle of $0^{\circ}$ or $360^{\circ}$ indicates red hue, while angles of $270^{\circ}, 180^{\circ}$ and $90^{\circ}$ indicate blue, green and yellow hue respectively. The hue angle value corresponds to whether the object is red, orange, yellow green, blue, or violet (Mohammadi et al., 2008).

Hue angle $(\mathrm{H})=\arctan \left(\frac{b}{a}\right)$

Colour kinetics for dehydrated mushroom during storage: The variation in colour parameters for dehydrated mushroom sample during storage was represented by a mathematical equation of the following form:

$$
\frac{\partial c}{\partial t}=x c^{n}
$$

Where, 
$\mathrm{C}$ is the colour parameter measured

$\mathrm{T}=$ storage period (in days)

$\mathrm{K}=$ rate constant which depends upon temperature and water activity

$\mathrm{N}=$ power factor also called the order of reaction

$$
\frac{\partial c}{\partial t}=\text { rate of change of } C \text { with time }
$$

A negative sign was used if deterioration was the loss of $\mathrm{C}$ and a positive sign if it was for production of an undesirable change in stored sample. In zero order reaction rate was independent of the colour parameter. For a degradation reaction:

$$
-\frac{\partial c}{\partial t}-k
$$

This by integration results in,

$$
C=C_{i}-k t
$$

Where, $C_{i}$ is the quality parameter at time zero days. The mathematical expression for a first order degradation reaction is as follow:

$$
-\frac{\partial c}{\partial t}=\mathrm{kcc}
$$

Which by integration this equation becomes,

$$
C=C_{i} e^{-k t}
$$

Texture Analysis: Texture of the dried mushroom flakes was determined with the help of Texture Analyzer (Model TA-XT2i, Stable Microsystems Ltd. UK). The samples were compressed by spherical probe. The pre-test speed was set at $1.5 \mathrm{~mm} / \mathrm{s}$, post test speed was set at $10 \mathrm{~mm} / \mathrm{s}$ whereas; test speed of $2 \mathrm{~mm} /$ $\mathrm{s}$ was set during compression. The height of the peak during compression cycle was defined as hardness (g-f).

Rehydration Characteristics: The rehydration ratio of dried mushroom flakes was determined by soaking dried flakes with a defined weight (approx. $5 \mathrm{~g}$ ) in boiling distilled water at $95{ }^{\circ} \mathrm{C}$ for 20 minutes. The flakes were removed, dried off with filter paper and weighed. In order to minimize the leaching losses, water bath was used for maintaining the defined temperature (Ranganna 1986). Rehydration ratio of the samples was computed as follows:

$$
\text { Rehydration ratio }=\frac{M_{1}}{M_{d}}
$$

Where,

$\mathrm{M}_{\mathrm{r}}=$ Mass of rehydrated sample, $\mathrm{g}$;

$\mathrm{M}_{\mathrm{d}}=$ Test mass of dehydrated sample, $\mathrm{g}$.

Moisture analysis: The moisture content of the dried flakes was determined gravimetrically according to AOAC (2005) method. The loss in weight was noted and expressed as moisture (\%) with the following formula:

$$
\text { Moisture }(\%)=\frac{\text { loss in weight }(\mathrm{g}) \times 100}{\text { weight of sample }(\mathrm{g})}
$$

Water activity $\left(\mathbf{a}_{\mathbf{w}}\right)$ : Water activity is the amount of water that is available to the microorganisms for their growth. Water activity $\left(a_{w}\right)$ is the ratio of water vapour pressure of the food to the water vapour of pure water under the same conditions. It is expressed as

$$
\text { water activity }\left(\mathrm{a}_{\mathrm{w}}\right)=\frac{\mathrm{p}}{\mathrm{p}_{\mathrm{o}}}
$$

Where, $p=$ water vapour pressure of the food; $p_{0=}$ water vapour pressure of pure water.

Water activity of the samples was measured using digital water activity meter. The samples were placed in a standard measuring cup provided with the water activity meter, and were sealed against a sensor block. Reading was recorded which will displayed on the screen after few minutes.

Ascorbic acid: The ascorbic acid content in the fresh and dried mushroom slices was determined by 2,6dichlorophenol-indophenol visual titration method (Ranganna, 1986). The ascorbic acid content of the samples was calculated by the following formula.

$$
\text { Ascorhir acid, } \frac{\mathrm{mg}}{100 \mathrm{~g}}=\frac{\text { Titre } \mathrm{X} \text { Dye factorX Volume extractX } 100}{\text { Aliquotof extract X Whight of zample taken }}
$$

Organoleptic evaluation: A panel of fifteen members was drawn from the teaching, non-teaching staff and M.tech scholars from the Department of Processing and Food Engineering, PAU. They were asked to assess the overall quality of dried salted flakes of oyster mushrooms taking into account the following attributes: appearance, colour, texture, flavour and overall acceptability on a 9-point hedonic scale (9-like extremely, 5-neither like nor dislike and 1-dislike extremely) and the readings are expressed in percentage. The values of overall acceptability have been given in the present study.

Statistical Analysis: The results were statistically analyzed to estimate the significance between packaging material, storage duration and storage conditions on the quality of dried flakes. The analysis was done using CPCS1 statistical software package. Means were computed and least square difference (LSD) was calculated at $5 \%$ of significance $(\mathrm{P} \leq 0.05)$.

\section{RESULTS AND DISCUSSION}

Dehydration has been extensively utilized for decades as one of the principal food preservation techniques. The intent of storage studies of dehydrated product was to produce shelf stable foods with superior quality. The different quality attributes of dehydrated oyster mushrooms during storage period are discussed and graphical representations are presented below. Means were computed and least square difference (LSD) was calculated at $5 \%$ of significance using CPCS1 software, for storage studies of oyster mushrooms.

Colour: Colour of mushrooms is an essential quality aspect because colour is regarded as the foremost quality consideration for customer appeal (Ahvenainen, 
1996). The effect of storage period on colour kinetics of dehydrated mushroom flakes packed in LDPE and HDPE and kept under different storage conditions (ambient and refrigeration) was observed. The values of $\mathrm{L}, \mathrm{a}, \mathrm{b}$ and colour change $(\Delta \mathrm{E})$ obtained from the storage study of $P$. sajor-caju mushrooms has been presented in Fig.1. A steady and considerable drop off of $\mathrm{L}$ values was observed in all samples during the storage. Comparable trend was also noticed for white button mushrooms in an earlier investigation (Khana et al., 2014). The change in the $\mathrm{L}$ value of dehydrated samples has been taken as a measurement of brightness, which reduced from 48.15 to 40.89 during storage. However, the highest $L$ value was observed as 48.15 for LDPE-R and HDPE-R after 15 days of storage. Whereas, the lowest was observed to be 40.89 for LDPE-A after 90 days of storage. The 'a' value increased with increase in storage. The highest ' $a$ ' value was observed as 7.18 for LDPE-A and lowest as 4.2 for LDPE-R and HDPE-R after 90 and 15 days of storage. An increase of the $b$ value was observed during storage period under different packaging material and storage conditions. The highest ' $b$ ' value was observed as 17.63 for LDPE-A after 90 days of storage and lowest as 10.78 for all samples stored in refrigerated condition after 15 days of storage. The value ' $b$ ' indicated the yellowness of the stored sample. The colour change $(\Delta E)$ of dried oyster mushroom flakes was found to increase along the storage period. This was probably due to the absorption of moisture as a consequence of an inadequate barrier provided by the package which resulted in much colour variation with respect to initial colour variation of dehydrated product. The rate of increase of colour change was found to be higher for 90 days stored product. The highest ' $\Delta \mathrm{E}$ ' value was observed as 19.94 for LDPE-A and lowest as 10.445 for LDPE-R and HDPE-R after 90 and 15 days of storage respectively.

Further, the experimental data pertaining to chroma and hue value in storage studies of mushrooms was also calculated. It was found that chroma increased with increase in storage time. On the other hand, decreased value of hue with storage time indicated that the hue value closely follow the ' $b$ ' value i.e., higher the ' $b$ ' value, higher would be the hue angle indicating darkening/yellowing of the dried mushroom product along the storage period. The chroma values varied between 11.58-19.04. The highest chroma value was observed as 19.04 for LDPE-A after 90 days of storage and lowest value of 11.58 was obtained for LDPE-R after 15 days of storage. The hue angle varied between 68.02-71.42 (Fig. 2). The statistical analysis also supported the fact that the values $\mathrm{L}, \mathrm{a}, \mathrm{b}$ and $\Delta \mathrm{E}$ values was significantly $(\mathrm{p} \leq 0.05)$ affected by the packaging material used during storage. The coefficient of variation (CV) was found to be 37.28, 118.7, 59.53 and 57.27 for $\mathrm{L}, \mathrm{a}, \mathrm{b}$ and $\Delta \mathrm{E}$ respectively. The critical difference $(\mathrm{CD})$ was found to be $6.8,6.6,4.9$ and 4.8 for $\mathrm{L}, \mathrm{a}, \mathrm{b}$ and $\Delta \mathrm{E}$ between different packaging material used in storage studies, whereas there existed no significant difference along storage duration as well as at different storage conditions. For the mathematical modeling of colour values of $L, a, b$; it was observed that $b, \Delta \mathrm{E}$, Hue and Chroma values were fitted to the zero-order kinetic model; on the other hand, the values of $L$ and $a$ values followed a first-order kinetic model respectively. The kinetic rate constant of $L, a$ and $b$ were more when stored in ambient temperature as compared to refrigerated temperature. This implies that with change in storage condition from refrigeration to ambient, the degradation rate of colour becomes faster as a result of high moisture absorption inside the food under ambient. The values of $L, a, b, \Delta \mathrm{E}$, Hue and Chroma obtained from the storage experimental data were fitted to kinetics models i.e. zero order and first order. The estimated kinetic parameters of these models and the statistical values of coefficients of determination $\mathrm{R}^{2}$ for dehydrated samples has been given in Table 1 and 2 . The highest $L, a, b, \Delta \mathrm{E}$, Hue and Chroma was found to be $48.851,4.414,12.688,12.375,13.431$ and 70.566 respectively.

Texture: Texture is one of the most important properties connected to product quality for the acceptability of food by consumers. Changes to the texture of solid foods are an important cause of quality deterioration. Factors that affect texture include moisture content, composition, variety, $\mathrm{pH}$, product history (maturity), and sample dimensions. Texture is also dependent on the method of dehydration. High air temperatures cause complex chemical and physical changes to the product surface and the formation of hard impermeable skin (case hardening). This reduces the rate of drying and produces a food with a hard outer surface and a moist interior (Anonymous, 2014). This is minimized by controlling the drying conditions to prevent excessively high moisture gradients between the interior and the outer surface of the dried food. On rehydration the product of this kind absorbs water more slowly rather incomplete and does not regain the firm texture associated with the fresh material (Anonymous, 2014). Hardness in mushroom flakes decreased with increase in storage time in all storage packs. Comparable trend was also noticed for white button mushrooms in an earlier investigation (Khana et al., 2014). The lowest hardness of dehydrated sample was observed as $654.456 \mathrm{~g}$-f for LDPE-A and highest as 1552.66 for HDPE-R after 90 and 15 days of storage. The effect of storage condition, duration of storage and packaging material on hardness of stored product has been presented in Fig. 2. The statistical analysis indicated that there existed no significant $(\mathrm{p} \leq 0.05)$ difference with respect to hardness of the flakes between the packaging materials, along storage duration at different storage condition. The $\mathrm{CV}$ was found to be 86.84. The $\mathrm{CD}$ was found to be 
non-significant between different packaging materials, along storage duration at different storage conditions.

Rehydration characteristics: The rehydration tests were conducted to evaluate the reconstitution qualities of dehydrated mushroom samples. In the storage study it was observed that rehydration ratio reduced with increase in storage duration in all storage packs. This must be due to permeability of moisture in packages during storage of oyster mushroom flakes. The lowest rehydration ratio of dehydrated sample was observed as 0.51 for LDPE-A and highest as 1.6 for HDPE-R after 90 and 15 days of storage respectively. The effect of storage condition, duration of storage and packaging material on rehydration ratio of stored mushroom product has been presented in Fig. 2. The CV was found to be 175.14 . The CD was found to be 7.54 between the packaging materials, and there existed no significant difference along storage duration at different storage condition.

Moisture content: Moisture content has a decisive influence on the final quality of the dehydrated product, such as texture, colour and nutritional value. During storage, the packaging material used for the srorage of dried products is much influenced by the product moisture variation (Weinberg et al., 2008). The effect of storage period on moisture content of dehydrated oyster mushroom flakes stored in LDPE and HDPE, and stored under ambient and refrigeration conditions has been shown in Fig. 3. It was observed that moisture content increased with increase in storage duration irrespective of packaging materials and storage conditions. The highest moisture content was observed as $10.41 \%$ for LDPE-A and lowest as 5.71 $\%$ for HDPE-R after 90 and 15 days of storage respectively. Packaging under appropriate storage condition plays an important role on protecting dehydrated food as it also influence from outside atmosphere and other damages. The CV was found to be 100.03. The CD was found to be 6.16 between the packaging materials, and there existed no significant difference along storage duration at different storage condition.

Water activity: Dehydrated foods have moisture content below $10 \%$ and a water activity 0.6 or below. They are hard and firm, resistant to microbial deterioration. Water activity is an important factor in product preservation because physical-chemical and microbiological alterations that occur during processing and storing of a food product depend on it. The effect of storage period on water activity of dehydrated mushroom flakes in LDPE and HDPE, kept under ambient and refrigeration conditions has been shown in Fig. 3. It showed that there was a similar change in water activity of the stored product that has occurred as in the case of moisture content. The water activity was found to increase with increase in storage duration in all storage packs. The highest water activity was observed as 0.704 for LDPE-A and lowest as 0.468 for HDPE-R after 90 and 15 days of storage. It was also observed
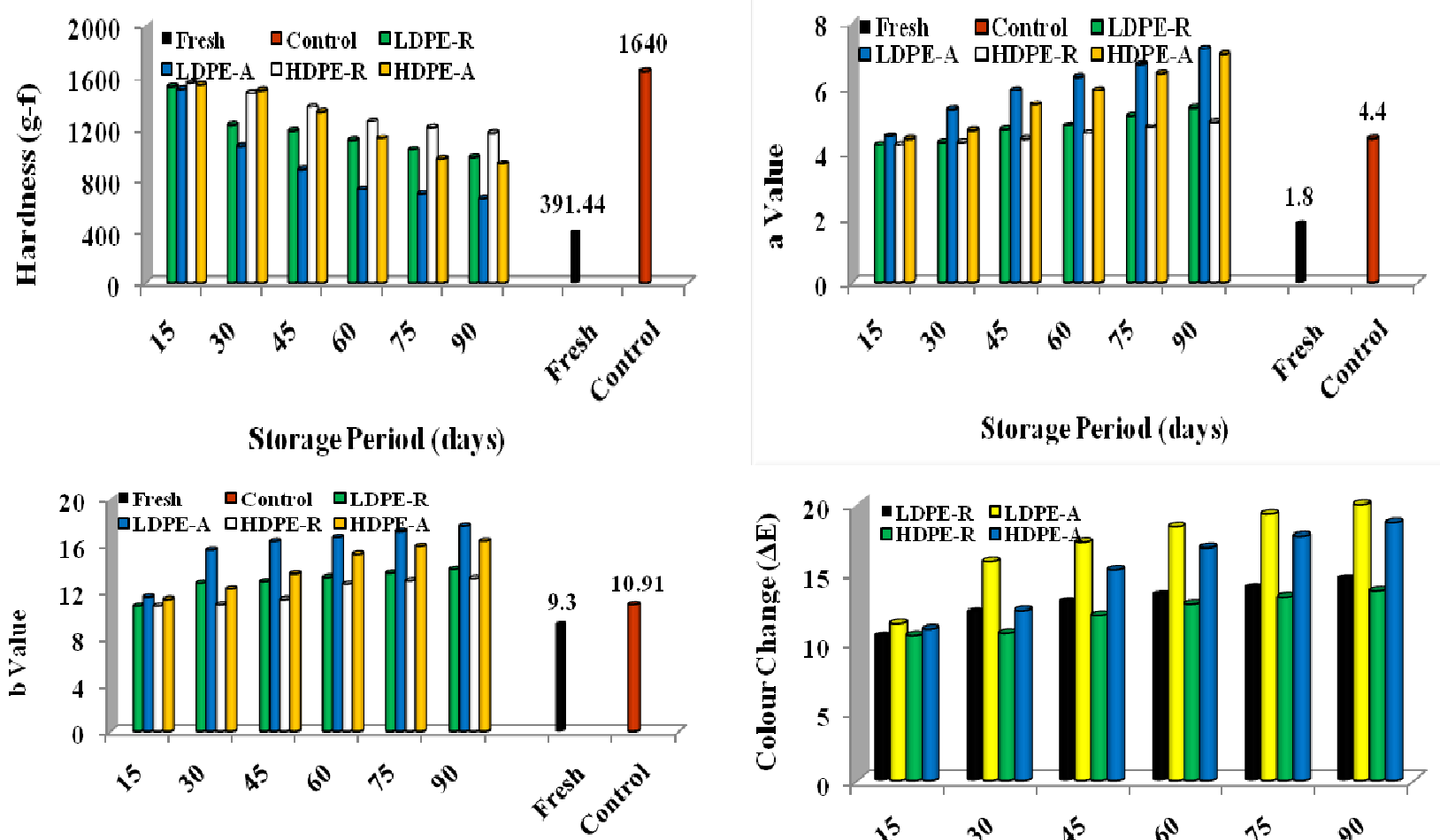

Storage Period (days)

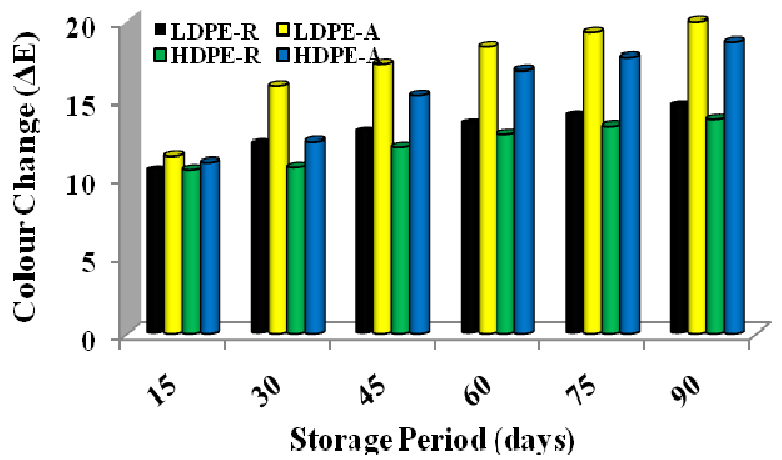

Fig.1. Effect of packaging material, storage condition and duration on $L, a, b$ and colour change ( $\triangle E)$ of dried salted mushroom flakes. 
that the packaging material used in the storage study had significant $(\mathrm{p} \leq 0.05)$ influence on the water activity of dried flakes during storage. The $\mathrm{CV}$ was found to be 186.69. The CD was found to be 7.68 between the packaging materials, and there existed no significant difference along storage duration at different storage condition. Ascorbic acid: The water-soluble vitamins are expected to be partially oxidized during processing and storage. Ascorbic acid are soluble until the moisture content of the food falls to below critical levels and react with solutes at higher rates as drying proceeds.
Ascorbic acid is sensitive to higher temperatures at higher moisture contents. Several research studies have shown that the maximum amount of ascorbic acid degradation occurs at specific (critical) moisture levels. The critical moisture level appears to vary with the different products (product being dried and/or the dehydration process). Short drying times, low temperature storage, and low moisture and oxygen levels during storage are necessary to avoid quality deterioration. To optimize ascorbic acid retention, the product should be dried at a low initial temperature when the moisture

Table 1. The estimated kinetic parameters and the statistical values of zero and first morder models for $L, a$ and $b$ value under different storage conditions for salt osmosed dehydrated mushrooms.

\begin{tabular}{|c|c|c|c|c|c|c|c|}
\hline \multirow{2}{*}{ Stored samples } & \multirow{2}{*}{ Colour parameter } & \multicolumn{3}{|c|}{ Zero order } & \multicolumn{3}{|c|}{ First order } \\
\hline & & $\mathrm{C}_{0}$ & $\mathbf{k}_{\mathbf{0}}$ & $\mathbf{R}^{2}$ & $\mathrm{C}_{0}$ & $\mathbf{k}_{1}$ & $\mathbf{R}^{2}$ \\
\hline LDPE-R & 'L' value & 48.3 & 0.041 & 0.932 & 48.348 & 0.001 & 0.936 \\
\hline LDPE-A & & 47.341 & 0.08 & 0.873 & 47.561 & 0.002 & 0.885 \\
\hline HDPE-R & & 48.787 & 0.039 & 0.952 & 48.825 & 0.001 & 0.954 \\
\hline HDPE-A & & 48.645 & 0.83 & 0.935 & 48.851 & 0.002 & 0.943 \\
\hline LDPE-R & 'a' value & 3.9 & -0.016 & 0.978 & 3.954 & -0.003 & 0.982 \\
\hline LDPE-A & & 4.19 & -0.034 & 0.979 & 4.414 & -0.006 & 0.961 \\
\hline HDPE-R & & 4.013 & -0.01 & 0.982 & 4.034 & -0.002 & 0.985 \\
\hline HDPE-A & & 3.773 & -0.036 & 0.99 & 4.001 & -0.006 & 0.989 \\
\hline LDPE-R & 'b' value & 11.012 & -0.035 & 0.799 & 11.149 & -0.003 & 0.781 \\
\hline LDPE-A & & 12.253 & -0.068 & 0.74 & 12.688 & -0.004 & 0.706 \\
\hline HDPE-R & & 10.026 & -0.037 & 0.921 & 10.148 & -0.003 & 0.919 \\
\hline HDPE-A & & 10.317 & -0.072 & 0.97 & 10.74 & -0.005 & 0.954 \\
\hline
\end{tabular}

Table 2. Kinetic parameters and the statistical values of zero and first order models for colour change, chroma and hue value under different storage conditions for salt osmosed dehydrated mushrooms.

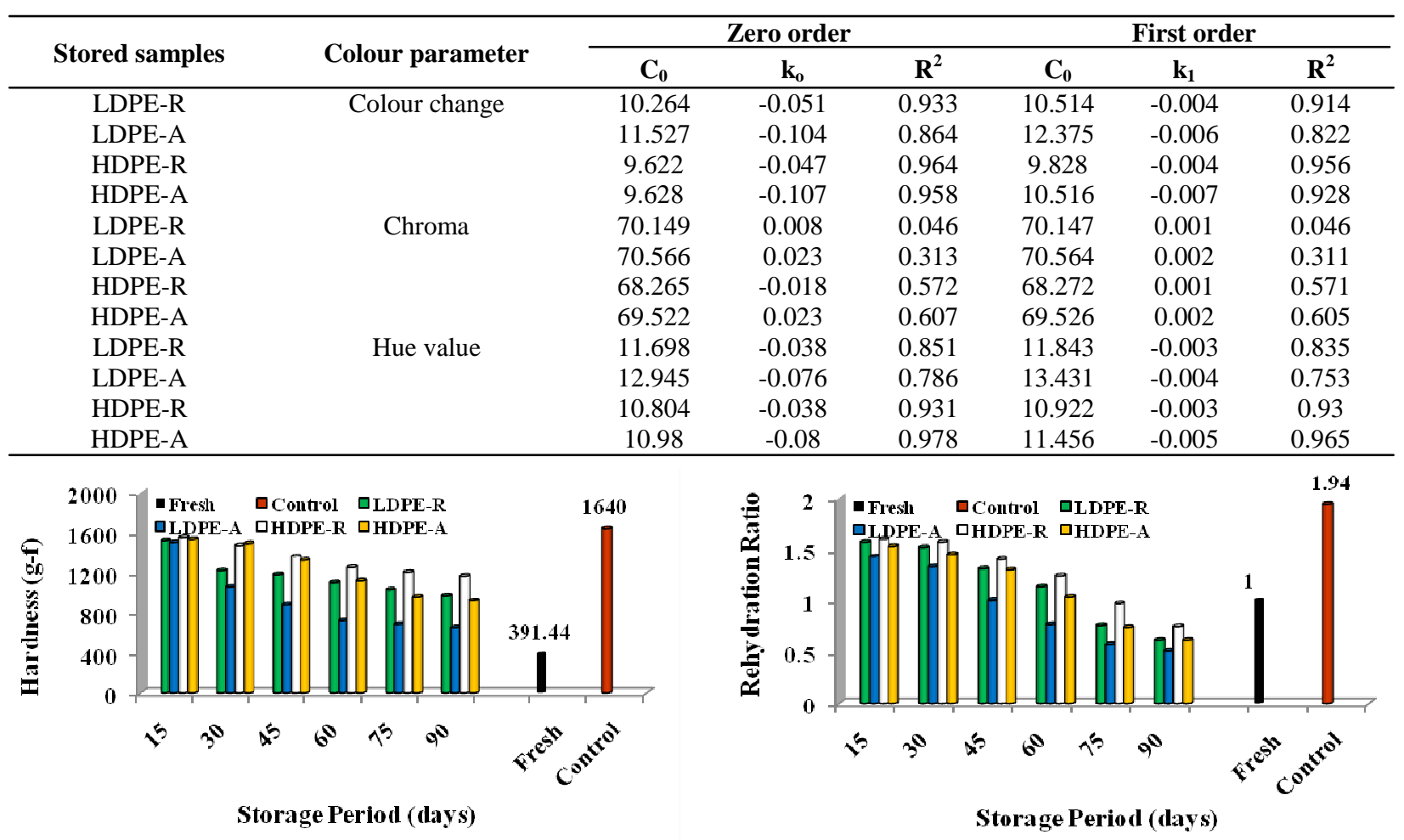

Fig. 2. Effect of packaging material, storage duration and condition on hardness and rehydration characteristics of dried salted mushroom flakes. 


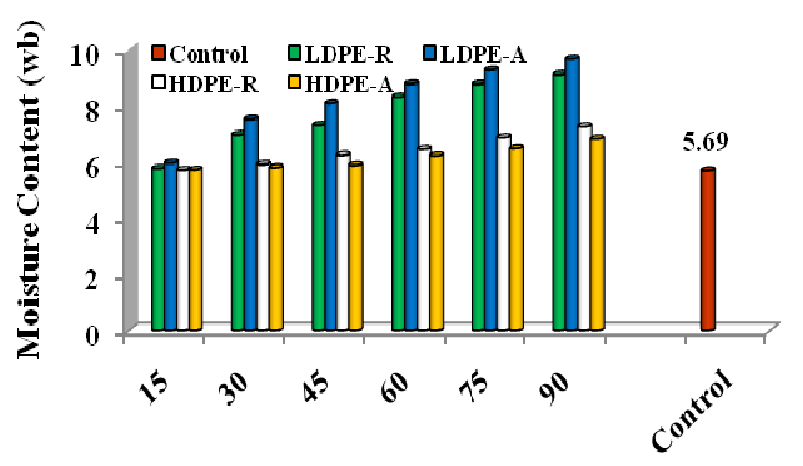

Storage Period (days)

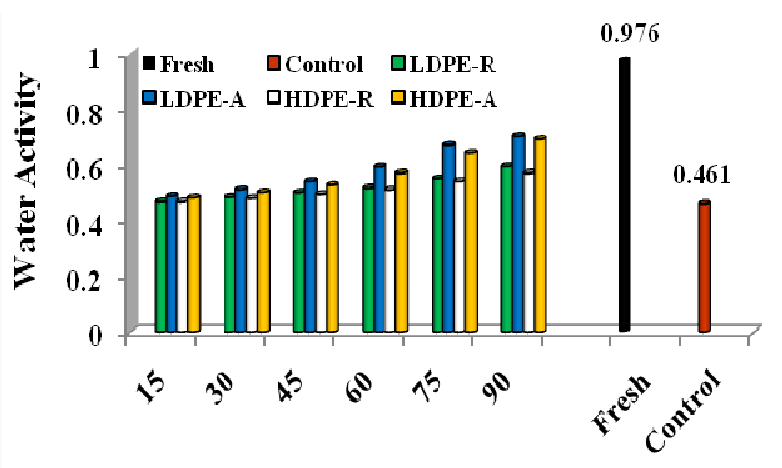

Storage Period (days)

Fig. 3. Effect of packaging material, storage condition and duration on moisture content and water activity of dried salted mushroom flakes
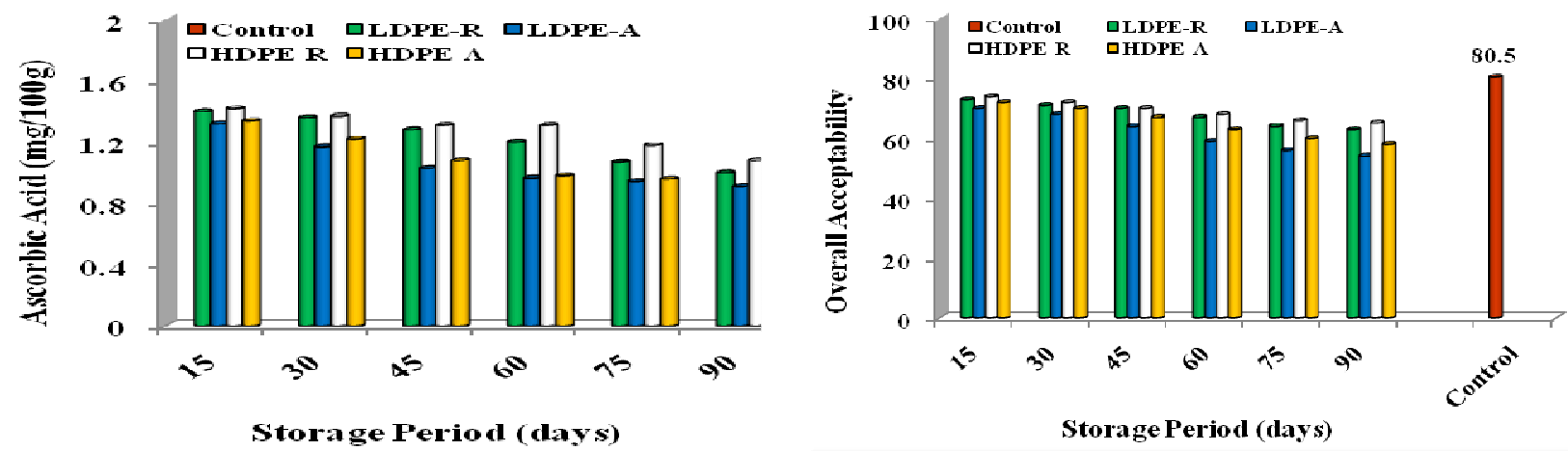

Fig. 4. Effect of packaging material, storage time and temperature on ascorbic acid and overall acceptability of dried salted mushroom flakes.

content is high since ascorbic acid is highly heat sensitive at higher moisture contents. The temperature can then be increased along progress in drying and ascorbic acid becomes more stable due to reduction in moisture (Anonymous, 2014). It was observed that ascorbic acid decreased persistently with increase in storage time in all storage packs of dried mushrooms. Similar trend was also noticed for Flammulina velutipes mushrooms in an earlier investigation (Donglu et al., 2016). This was probably due to permeability of moisture inside the packaging material, and oxidation reaction must have taken place in packages during storage of oyster mushroom flakes. Further, rate of decrease of ascorbic acid was observed to be slower for samples stored in HDPE-R as compared to samples stored in LDPE packaging materials. The highest ascorbic acid content of stored sample was observed as $1.42 \mathrm{mg} / 100 \mathrm{~g}$ in HDPE-R, and lowest as 0.91 for LDPE-A after 15 and 90 days of storage respectively. The effect of storage condition, duration of storage and packaging material on ascorbic acid content of stored flakes was observed and presented in Fig. 4. The CV was found to be 174.25. The CD was found to be 7.53 between the packaging materials, and there existed no significant difference along storage duration at different storage condition.

Overall acceptability: Sensory or organoleptic scores indirectly signify product shelf-life and stability, which refers to the end of consumer acceptability, and is the time at which majority of consumers are displeased with the product quality (Labuza and Schmidl, 1985). Darkening and loss of flavour are the major types of deteriorations of dried food products during storage. Storage temperature, light, packaging material, moisture content, anti-microbial treatment and trace elements present in the dried product are major factors affecting storage stability. Organoleptic evaluation of the dried mushroom flakes was carried out to obtain preliminary information on consumer preference. The osmo-cum microwave dehydrated mushroom flakes was found to be acceptable in all sensory quality parameters and showed a small dwindle in overall acceptability values with respect to packaging material and storage condition with passage of time, in storage studies of mushrooms. The highest product acceptability was observed to be 74 (considering hedonic rating of $9=100 \%$; whereas $1=9 \%$ ) for HDPE-R and lowest as $54 \%$ for LDPA-A and HDPE-A after 15 and 90 days of storage respectively (Fig. 4). Nevertheless, the overall acceptability for all the samples reduced with storage duration irrespective of the packaging material and storage condition. The CV was found to be 47.76. The CD was found to be non significant between different packaging materials, along storage duration at different storage conditions. 


\section{Conclusion}

From the present investigation it was conluded that storage stability is influenced by the organoleptic, physical and chemical changes that takes place in the dried product during storage and the rates at which these changes occur. Darkening and loss of flavour are the major visible deteriorations of dried products in storage. Prior to storage, mushroom samples were pretreated with salt and were dried by microwave drying technique to a moisture content of around $6 \%$ (w.b.). Assessment of quality attributes; colour, texture, rehydration, moisture variation with storage duration, water activity, ascorbic acid and organoleptic evaluation was carried out systematically. It was found that mushroom flakes were highly acceptable upto two months of storage duration that have packed in high density poly ethylene that were stored under refrigeration condition with higher overall acceptability with minute changes in the quality attributes. However, mushrooms stored in LDPE lost the quality attributes after a month of storage. The statistical data generated in the present investigation will be informative for the researchers and entrepreneurs involved in the post-harvest processing and value addition of dried mushroom products.

\section{REFERENCES}

Ahvenainen, R. (1996). New approaches in improving the shelf life of minimally processed fruits and vegetables. Trends in Food Science and Technology, 7: 179-187

Anonymous. (2014). Quality of dried foods and deteriorative reactions during drying. (http://www.unido.org/ fileadminimport/32142_31QualityofDriedFoods.14.pdf)

AOAC. (2005). Official methods of analysis, $18^{\text {th }}$ edn. Association of official analytical chemists. Virginia, USA.

Chang, R. (1996). Functional properties of edible mushrooms. Nutrition Reviews, 54: 391-393

Chua, K. J., Mujumdar, A. S., Hawlader, M. N. A., Chou, S. K. and Ho, J. C. (2001). Batch drying of banana pieces - effect of stepwise change in drying air temperature on drying kinetics and product colour. Food Research International, 34:721-731

Clary, C. D., Wang, S. J. and Petrucci, V. E. (2005). Fixed and incremental levels of microwave power application on drying grapes under vacuum. Journal of Food Science. 70:344-349

Cui Z. W., Xu S. Y. and Sun D. W. (2004). Microwavevacuum drying kinetics of carrot slices, Journal of Food Engineering, 65:157-164

Donglu, F., Wenjian, Y., Kimatu, B.M., Mariga, A.M., Liyan, Z., Xinxin, A. and Qiuhui, H. (2016). Effect of nanocomposite-based packaging on storage stability of mushrooms (Flammulina velutipes). Innovative Food Science and Emerging Technologies, 33: 489-497

Kanagasabapathy, G., Chua, K. H., Malek, S. N. A., Vikineswary, S. and Kuppusamy, U. R. (2014). AMP-activated protein kinase mediates insulin-like and lipo-mobilising effects of $\beta$-glucan-rich polysaccharides isolated from Pleurotus sajor-caju (Fr.), Singer mushroom, in 3T3-L1 cells. Food Chemistry. Pp198-204.
Kaushal, P. and Sharma, H. K. (2014). Osmo-convective dehydration kinetics of jackfruit (Artocarpus heterophyllus). Journal of the Saudi Society of Agricultural Sciences. http://dx.doi.org/10.1016/j.jssas.2014.08.001. Article in press.

Khan, M. A., Ruhul, Amin, S. M., Uddin, M. N., Tania, M. and Alam, N. (2008). Comparative study of the Nutritional composition of oyster mushroom cultivated in Bangladesh. Bangladesh J. Mushroom, 2: 9-14

Khana, Z.U., Aisikaera, G., Khanb, R.U., Bua, J., Jianga, Z., Nia, Z. and Ying, T. (2014). Effects of composite chemical pretreatment on maintaining quality in button mushrooms (Agaricus bisporus) during postharvest storage. Postharvest Biology and Technology. 95:36-41

Khraisheh, M. A. M., Cooper, T. J. R. and Magee, T. R. A. (1997). Shrinkage characteristic of potatoes dehydrated under combined microwave and convective air conditions. Drying Technology International. 15: 1003-1022

Labuza,,T.P., and Schmidl, M.K. (1985). Accelerated shelf life testing of foods. Food Technology. 39: 57-54

Mattila, P., Konko, K. and Eurola, M. (2001). Contents of vitamins, mineral elements, and some phenolic compounds in cultivated mushrooms. Journal of Agriculture and Food Chemistry. 49: 2343-2348

Maheshwari, S. (2013). A Guide for White Button Mushroom (Agaricusbisporus) Production. Open Access Scientific Reports. 2: 1-4

Mohammadi, A., Rafiee, S., Emam-Djomeh, Z. and Keyhani, A. (2008). Kinetic models for colour changes in kiwifruit slices during hot air drying. World Journal of Agricultural Sciences, 4

Petrotos, K. B. and Lazarides, H. N. (2001). Osmotic concentration of liquid foods. Journal of Food Engineering, 49:201-206

Phan, C. W., David, P., Naidu, M., Wong, K. H. and Sabaratnam, V. (2014). Therapeutic potential of culinary-medicinal mushrooms for the management of neurodegenerative diseases: diversity, metabolite and mechanism. Critical Reviews of Biotechnology. Print in progress.

Prabhanjan, D. G., Ramaswamy, H. S. and Raghavan, G. S. V. (1995). Microwave- assisted convective air drying of thin layer carrots. Journal of Food Engineering. 25: 283-293.

Ranganna, S. (1986). Handbook of analysis and quality control for fruits and vegetable products $\left(2^{\text {nd }} e d\right.$. $)$. Tata mcgraw hill publishing company limited. New delhi. Pp. 171-174.

Rastogi, N. K. and Raghavarao, K. (1997). Water and solute diffusion coefficients of carrot as a function of temperature and concentration during osmotic dehydration. Journal of Food Engineering. 34: 429-440

Vega-Mercado, H., Gongora-Nieto, M. M. and BarbosaCanovas, G. V. (2001). Advances in dehydration of foods. Journal of Food Engineering. 49:271-289.

Weinberg, Z. G., Yan, Y., Chen, Y., Finkelman, S., Ashbell, G. and Navarro, S. (2008). The effect of moisture level on high-moisture maize (Zea mays L.) under hermetic storage conditions-in vitro studies. Journal of Stored Products Research. 44: 136-144

Williams, B., Marsales, H., Millen, A., Burton, H., Browne, R. and Horvath, P. (2014). Effect of chronic mushroom intake on functional fitness in older men and women. The FASEB Journal, 28:1 